\title{
Sistema Único de Saúde (SUS) aos 30 anos
}

\section{Thirty years of the Unified Health System (SUS)}

Jairnilson Silva Paim ${ }^{1}$

${ }^{1}$ Instituto de Saúde Coletiva, Departamento de Saúde Coletiva I, Universidade Federal da Bahia. R. Basílio da Gama sn, Canela. 40110-040 Salvador BA Brasil.

jairnil@ufba.br

\begin{abstract}
This article, which aims to explore questions relating to SUS at 30 and to dialogue with other studies, presents an overview of the positive drivers, the obstacles and the threats to Brazil's Unified Health System. It points to a lack of prioritizing the SUS on the part of the government, underfunding and attacks on the system made by capital's policies. The article also suggests that one of the most significant threats to SUS is the financialization of health, linked to the financial dominance. It concludes by arguing that the SUS is not consolidated, justifying alliances between democratic, popular and socialist forces, with new strategies, tactics and forms of organization to face up to the power of capital and its representatives in society and in the State.

Kew words Unified Health System, Health poli$c y$, Brazilian health reform
\end{abstract}




\section{Introduction}

The Democratic-Popular and Hope and Change projects formulated during the democratic transition in Brazil were not privileged by the political forces that had the historic opportunity to occupy the federal government after the promulgation of the Citizen's Constitution ${ }^{1}$. The coup by the forces of capital, which has been waged since 2014 through the media, segments of the middle class and parliament, with the approval of the judiciary, ruptured the social pact that was established at the end of the dictatorship, attacking democracy and suppressing various civil, social and political rights.

The lack of priority given to the SUS, and the attacks aimed at dismantling it, were reinforced by the economic crisis, by fiscal austerity policies and, especially, by Constitutional Amendment No. 95 (EC-95/2016), which freezes the public budget for twenty years ${ }^{2}$. The Temer government both continued and intensified the existing hegemony against the SUS, reducing it even further and running the risk that it may become a simulacrum.

The fact is that the SUS was implemented; however, it has not been consolidated. Recent studies ${ }^{3-5}$ have indicated more complex phenomena in the area of health than mere analyses of conjuncture can highlight, and they raise the following questions: a) what are the positive vectors that have sustained the SUS?; b) what have been the obstacles and threats to the SUS?; c) what are the alternatives?; d) how is it possible to broaden the basis of social and political support?; e) will the SUS end?; f) what strategies and tactics can be used to consolidate the SUS?

The aim of this article is to dialogue with some of the studies and questions regarding the SUS on it's thirtieth anniversary.

\section{What are the positive vectors that have sustained the SUS?}

Inspired by values such as equality, democracy and emancipation, the SUS is an integral feature of the Brazilian Constitution, ordinary legislation, and technical and administrative norms. The Brazilian Health Reform Movement (MRSB), which supports the SUS, is composed of entities with more than four decades of history and commitment to the defense of the universal right to health, such as the Brazilian Center for Health Studies (Cebes) and the Brazilian Association of Collective Health (Abrasco). The SUS is also supported by other organizations such as the Brazilian Association of Health Economics (Abres), the Rede Unida, health councils (national, state and municipal), the National Association of Public Ministry in Defense of Health (Ampasa), the National Conference of Brazilian Bishops (CNBB), the National Council of Health Secretariats (Conass), the National Council of Municipal Health Secretariats (Conasems), the popular health movement, and others.

The SUS incorporates a network of teaching and research institutions, such as universities, public health institutes and schools, which interact with state and municipal secretariats, the Ministry of Health, agencies and foundations. This network contributes to institutional sustainability because it enables groups of people to acquire knowledge, skills and values linked to SUS principles and directives. Many of these people support the SUS, even in difficult circumstances, and become militant in its defense. The training of health workers and other workers in universities and schools ensures the reproduction and dissemination of information and knowledge, as well as the appropriation of technical expertise.

Brazil has decentralized tasks and resources, increasing the supply and access to health services and actions, which has had an impact on health levels. This constitutional guideline, with a single command in each sphere of government, was implemented in less than a decade for twenty-seven federal units and almost 5,600 municipalities, ensuring community participation through conferences and councils, as well as creating agreements such as tripartite and bipartite inter-agency committees. This process of constructing the SUS has generated enthusiasm and commitment among health workers linked to the health secretariats and the Ministry of Health, despite the limitations imposed by management in the three spheres of government, which has generated dissatisfaction in public services.

Creative political-institutional engineering facilitated the production of basic operational norms, pacts, integrated agreed programming, a regionalization development plan and an investment master plan, which all contributed to the institutional sustainability of the SUS and to its materiality, expressed in establishments, teams, equipment and technology. Hence the legacy of the SUS regarding advances in the health surveillance system, sanitary control, pharmaceutical assistance, transplants, SAMU, the control of smoking, HIV/AIDS and blood quality. The National Immunization Program is the largest such 
program worldwide, resulting in self-sufficiency in terms ofimmunobiologicals. Primary healthcare is excellent, linkingapproximately $60 \%$ of the Brazilian population to family health teams.

Brazil has made progress in the development of health information systems, such as those related to mortality, hospital admissions and compulsory notification disease, which are important to monitor and evaluate policies, plans and programs.

It is also worth mentioning the formal recognition of the right to health that has made it possible to promote this achievement within Brazilian society, whether in manifestations of citizenship and in the media, or in culturally relevant judicial processes. All of them can evolve into a critical health conscience.

\section{What have been the obstacles and threats to the SUS?}

In ideological terms, the dominant values in Brazilian society tend more towards differentiation, individualism and distinction than toward solidarity, collectivity and equality. This negative aspect is aggravated by the limited social and political basis of the SUS, which does not rely on support from political parties or workers organized in centralized trade unions for the defense of the right to health which is inherent in citizenship, as occurs in other countries that have opted for a welfare state system.

The SUS faces resistance from some health professionals whose interests were not reflected in work management and health education policies. In addition to systematic criticism and opposition in the media, the SUS is confronted by major economic and financial interests related to health plan operators, advertising companies and the pharmaceutical and medical-hospital equipment industries.

The predominance of the doctrine of neoliberalism, precisely during the period of implementation of the SUS, together with the limitations of the welfare state in Europe and the economic crisis of 2008, represented a serious obstacle to the development of universal health systems. Likewise, the political-ideological proposal of universal health coverage sponsored by international organizations has reinforced this doctrine and weakened the civilizing values embodied in the SUS.

Although the Brazilian Constitution proclaims health to be the right of all and the duty of the state, the executive, legislative and judicial sectors of the Brazilian state have not ensured the objective conditions for the economic and scientific-technological sustainability of the SUS. Management problems, such as the lack of professionalization, the clientelist and partisan use of public institutions, the excessive number of positions of trust, the bureaucratization of decisions, and administrative discontinuity have all been highlighted, although the alternatives that have been posited imply the devaluation of health workers, through outsourcing and job insecurity.

Other negative aspects regarding the construction of the SUS can be identified in policies regarding medicines and pharmaceutical assistance, in the control of the Aedes Aegypti mosquito, and in the safety and quality of care. Factors such as the lack of public infrastructure; the lack of upward planning; difficulties with networking in terms of regionalization; and impasses in relation to changing healthcare models and practices have also compromized the implementation of universal and equal access to health services and actions. The hegemonic medical model has continued; centered more on disease than on health, on treatment rather than prevention or promotion, and on hospitals and specialized services rather than the community, territories and primary healthcare.

For a long period, chronic underfunding was identified as one of the major obstacles to the consolidation of the SUS. Several initiatives were taken to remedy this, such as the Provisional Contribution on Financial Transactions, EC29/2000 and the Health +10 Movement; however, these did not substantially change the financing structure, and public spending, such as the percentage of gross domestic product allocated for health, remained below that of private spending ${ }^{4}$.

Due to insufficient resources the SUS faces problems in maintaining its service network and remunerating its workers, which limits investments for the expansion of the public infrastructure. Faced with this reality, the decision to buy services in the private sector is attractive and the ideology of privatization is strengthened. Thus a passive boycott prevails due to public underfunding, and an active boycott gains momentum when the state rewards, recognizes and privileges the private sector through subsidies, deregulation and sub-regulation. The executive ensures a standard of financing for the private sector with the support of the National Bank for Economic and Social Development and the Caixa Econômica Federal (Federal Savings Ban) which is quite 
different from the public institutions of the SUS. This state action, through boycotts via executive, legislative and judicial channels compromizes the validity of the concept of social security, in addition to facilitating the privatization of health. With the approval of EC-95/2016, the chronic underfunding of the SUS was constitutionalized, crystallizing the difficulties accumulated since $1988^{4}$

The aformentioned obstacles are often highlighted in discussions about the SUS; however, what is often neglected is the impact of predatory public-private linkage, where private interests have predominated over the last thirty years. Because the threat presented by capital is not as visible as queues for health services, the lack of health professionals, or limited access to medicines, it has received less attention and investigation.

The privatization of health, which was present in the evolution of public policies even before the advent of the SUS, presents different configurations arising from the movement and circuits of capital in the health sector. Currently, public-private linkage presents new facets in the form of the financialization of health linked to financial dominance ${ }^{5}$. Recent studies ${ }^{3-5}$ have demonstrated the complexity of this new phase of public-private linkage through the sale of companies, their assets and customer portfolios, deepening the intermediation between providers and consumers, as well as forming new relationships between the state apparatus and financial capital (including international capital) ${ }^{5}$. This economic determination represents the greatest threat to the consolidation of the SUS.

\section{What are the alternatives to the SUS?}

The defense of the constitutional SUS and the SUS proposed by the Brazilian Health Reform Movement (RSB) indicate alternatives that run contrary to the segmentation and americanization of the Brazilian health system. Despite all its difficulties and fragilities, the SUS has produced significant achievements and results during the last three decades: its institutionality can be enhanced by its managers, public prosecutors, health councils and workers, consolidating resistance against its dismantling.

Alternative actions are not defined as techni$\mathrm{cal}$, re-emphasizing the argument that the greatest challenge to the SUS is political. Consequently, in addition to actions that are possible within civil society, it is necessary to recognize the need for action in political society, i.e. the state, its apparatus and its institutions. This means the possibility of acting together with executive, legislative and judicial powers, as well as the instruments of hegemony.

In the case of the executive, regardless of the actions of professionals and workers in SUS institutions at the municipal, state and federal levels, the definition of feasible alternatives is necessarily linked with government goals and actions. Thus, elections always represent an opportunity to discuss alternatives expressed within the programs of candidates, regardless of adverse circumstances, whether at the federal level or at the level of federated units.

From this perspective, it is possible to conceive of a dialogue in defense of the constitutional SUS and the democratic SUS in elections together with the forces and candidates of the left and center-left, with some possibilities also available in the center of the political spectrum. Alliances with the political center-right and right, which are in control at the federal or state level, are unviable because they are committed to dismantling the SUS. Thus, building a broad, democratic, popular and socialist bloc in defense of the RSB and the SUS should to be included in the political agenda of progressive forces.

\section{How is it possible to broaden the basis of social and political support for the SUS?}

Since the origins of the health movement there has always been concern about the basis of political support for the RSB/SUS. The commitment to involve health organizations, unions and popular sectorshas been much debated. Political parties and politicians linked to democratic forces were active in the constitutional process and preparation and enactment of the Organic Health Law. The implementation and operation of the Health Plenary represented a connecting point between these forces and resulted in a positive outcome regarding the implementation of the SUS.

The roles played by Conass and Conasems since the 1990s, together with the introduction of state and municipal councils, allowed the basis of support for the SUS to be expanded. The National Health Council (CNS) has demonstrated significant activism, mobilizing social groups and confronting certain government initiatives. Similarly, the expansion of municipal health managers has reinforced these social and political foundations. 
Nevertheless, the political coup of 2016 changed the correlation of forces in such way that some of there individual started supporting initiatives from the Ministry of Health that were criticized by the health movement. If it is not strictly correct to refer to these individuals as plotters behind the coup, it is also not appropriate to count on their support merely because of their positive attitudes in the past. Hence the need to maintain a dialogue so that contradictions can be explained and conflicts resolved.

Considering the peculiarities of the passive revolution in Brazil that has infiltrated the RSB process, it is fundamental to constitute praxis subjects (resistance subjects, new public servants, transformative subjects), both individual and collective, who are capable of defending the SUS, and antithesis subjects who are capable of unbalancing the binomial of conservation-change in favor of transformations, radicalizing democracy and the RSB ${ }^{6}$.

The constitution of subjects is not restricted to the pedagogical dimension; it can be performed at different levels (work, militancy and social struggles). In addition to the progressive social movements and entities of the MRSB (Cebes, Abrasco, Rede Unida, Abres, etc.) the crisis after the 2016 coup led to the founding of the People's Front without Fear and the Popular Brazil Front, among others, which have enabled mobilizations and political action against retrogression and attacks on democracy, centered around the No Reduction of Rights banner. Such movements tend to express themselves in the electoral process and in the configuration of political forces that conquer spaces within the federal and state spheres.

\section{Will the SUS end?}

This is an ever-present question in discussions about the SUS. Despite the attacks and blows that the SUS has suffered, including the boycotts by the Brazilian state, its extinction is unlikely. In addition to the relative strength of its supporters and militants, there are a number of interests linked to capital, to the state, and to the dominant classes that indicate that the SUS will be maintained, either as a means of legitimization or co-optation, or as a locus of accumulation, circulation and expansion of capital. Public-private linkage in the health field in Brazil has facilitated the economic and political strengthening of private companies to the detriment of the public interest, and independently of the constitution and legislation.
Even conceding that there is no such thing as a policy that is irreversible, the political agenda of these representatives of capital does not envisage the extinction of the SUS. On the contrary, the SUS as it exists has been organic to their business and there is no point in killing a goose that lays golden eggs. This real SUS, which partly represents itself as the SUS for the poor is already part of the common perceptions of managers, politicians, the media, health professionals and even the Brazilian population. It can reproduce in the present and in the future, even if restricted, depending on the dynamics and expansion of capital, as well as the responses of the health movement.

This reduced version of the SUS is mainly aimed at the poorest sectors of the population, who do not have access to the market, and it is limited to the typical public health roles of the prevention and control of health risks, damages and epidemics. Ensuring the implementation of high-cost procedures for the private sector ${ }^{5}$, it is far removed from the constitutional SUS and the democratic SUS proposed by the RSB ${ }^{1}$. It represents a mockery or simulation of the SUS.

\section{What strategies and tactics can be used to consolidate the SUS?}

This highly relevant question requires reflection: it is certainly one of the most difficult questions to answer. Firstly, because not every individual or actor is capable of defining a strategic design. This praxis - thought and action - requires not only the legitimacy of those who indicate strategies and tactics, but also, specifically, the ability to carry out concrete analyses of situations and political insight regarding the most appropriate moment for the organization of, and intervention in, reality. Accumulated experience and skills are fundamental to achieve effectiveness of action. Secondly, because isolated individuals or intellectuals are unable to answer this question, only collective individuals such as political parties or other organizations that have historical precedence and the ability to initiate action. It is the latter who deal with the dialectic of transparency/opacity ${ }^{7}$ and are able to choose the appropriate element of one or the other terms of the dichotomy, since it is not possible to reveal the game to one's opponents.

Three strategies were implemented in the development of the RSB process: the legislative-parliamentary; the technical-institutional; and the socio-community. Currently, faced with the limitations of political parties and the role of social 
movements, the search for political-cultural hegemony and the struggle for the radicalization of democracy imply the construction of equivalence between agendas and collective individuals, in addition to the capital-labor contradiction. Consequently, the work of Cebes since its relaunch in 2006, and especially its involvement in the June Days and the popular fronts after the 2016 coup, is an incentive to explore other strategies and tactics in the RSB process in defense of democracy, the SUS and social rights ${ }^{6}$.

However, proselytizing in defense of the SUS and the ideological practice of the health movement are not sufficient. Hence the need for periodic meetings of the RSB Forum and progressive linkage with national, state and municipal health councils in order to design strategies and establish tactics that are more appropriate to the situation, despite the limited participation of political parties.

By identifying movements of capital that have economic, political and ideological dimensions at the sectoral level, the alliances and unity required by democratic, popular and socialist forces will require exceptional organization in order to confront the power accumulated by entrepreneurs and their representatives within society and the apparatuses of the state.

Therefore, unity, flexibility and effectiveness are fundamental. The search for more organic organizational forms may suggest the creation of an executive secretariat so that the RSB Forum can act more quickly, avoiding the movement being halted or driven by facts. Consequently, some recent signs of withdrawal by Conass and Conasems in relation to the health movement should be considered and politically addressed to rebuild dialogues in defense of democracy, the RSB and the SUS.

\section{Conclusion}

An overview of the positive vectors, obstacles and threats in the thirty years since the advent of the SUS does not signify complacency regarding errors and misconduct. Besides strengthening the motivation for the struggles of those who defend the universal right to health, reflection on studies and questions about the SUS can reinforce certain strategies and create new ones for its preservation.

It is necessary to focus on the correlation of forces, which are highly unfavorable at present, and accumulate new energies for more propitious times, without neglecting actions that are required at the moment, as well as new organizational forms. This political practice requires the best of militancy and it calls for action in defense of the right to health and the SUS. If the state sabotages the SUS it is for civil society to fight for the RSB and for a universal, public health system of quality and effectiveness. It is the responsibility of the health movement to provide a more progressive element to the Brazilian passive revolution.

\section{References}

1. Paim JS. A Constituição Cidadã e os 25 anos do Sistema Único de Saúde. Cad Saude Publica 2013; 29(10):19271953.

2. Vieira FS. Crise econômica, austeridade fiscal e saúde: que lições podem ser aprendidas? Brasília: Ipea; 2016. [Nota técnica].

3. Monteiro MG. Trayectoria y cambios de dirección em las políticas públicas: análisis de la reforma del sistema sanitario brasileño (1975-2015) [tesis]. Barcelona: Universitad Autónoma de Barcelona; 2016.

4. Melo MFGC. Relações público-privadas no sistema de saúde brasileiro [tese]. Campinas: Universidade Estadual de Campinas; 2017.

5. Sestelo JAF. Planos e seguros de saúde do Brasil de 2000 a 2015 e a dominância financeira [tese]. Rio de Janeiro: Universidade Federal do Rio de Janeiro; 2017.

6. Paim JS. Reflexiones teóricas sobre sujetos de la práxis y sujetos de la antítesis para la Reforma Sanitaria Brasileña. Salud Colectiva 2017; 13(4):599-610.

7. Testa M. Pensamento estratégico e lógica de programação. O caso da saúde. São Paulo, Rio de Janeiro: Hucitec, Abraco; 1995. 